\title{
Design of 3-Level Inverter Using FIXCOM
}

\author{
R.Mohammed Abdullah ${ }^{1}$, S.Syed Abdul Haq ${ }^{2}$ \& P.Meenalochini ${ }^{3}$ \\ ${ }^{1,2,3}$ Assistant Professor, Department of EEE, Sethu Institute of Technology, Tamilnadu, India.
}

In the utility grid, the occurrence of a voltage drop on the transmission and distribution lines is due to the flow of reactive energy. It is advisable to regulate the voltage within a narrow range of its nominal value ( $\pm 5 \%$ range around its nominal values). Consequently, reactive power control is necessary to control dynamic voltage fluctuations under different system conditions and thus improve the performance and transmission of the distribution system. In this paper, a fixed three-phase voltage (VSI) source compensator is searched for. The paper aims to explain how STATCOM is used to improve the AC system power factor and voltage regulation, and thus improve the performance of transmission and distribution lines. A STATCOM fast fixed compensator is required to produce or absorb reactive energy in order to provide the necessary reactive energy balance in the transmission and distribution system. Modern reactive power compensation uses a voltage inverter (VSI). This STATCOM application has achieved a unit power factor transmission system, which reduces active energy loss by $38.7 \%$ thus reducing energy costs, as well as increasing the capacity o the transmission system.

Keywords: Voltage Regulation, Power Factor, VAR Compensation, Inverter, Total Harmonic Distortion.

\section{INTRODUCTION}

Modern power systems are designed to work efficiently to provide on-demand power to various load centers with high reliability. Power plants are often located in remote locations for economic, environmental and safety reasons [1]. Modern industrial processes rely on a large amount of electronic devices such as programmable logic controllers (PLCs) and adjustable speed motors. Thus, industrial loads become less tolerant of disturbances in power supplies such as voltage drop, voltage amplifications, voltage flashing and harmonics [2]. Voltage decreases are the most common and severe disturbances in industrial equipment [3]. The cause of the voltage drops can be the start of large loads, but they are mostly due to network errors [4]. Flexible alternating current transmission system (FACTS) is an alternating current transfer system that includes electronic power-based controllers and other fixed controls to enhance control power and flexibility of operation of the power system which improves system stability and makes better use of the existing power system [1].

STATCOM is a member of FACTS equipment. It is a power electronics regulator consisting of a voltage inverter (VSI) and alternately connected between the current electricity transmission and distribution networks (the grid) to protect sensitive loads from voltage drops [5]. A voltage source is created from a DC capacitor and STATCOM can exchange interactive power with the network. The STATCOM function is to keep the connected bus voltage at a constant value [6]. It can also supply some active power to the network if the DC power source is connected via the capacitor. STATCOM is usually installed in electrical networks with weak power factor or poor voltage regulation to alleviate these problems. In addition, it is used to improve the network voltage stability. It can simultaneously achieve various goals such as maintaining the pocket voltage (free from harmonic) in the load conveyor, eliminating current source harmonics, load balance, power factor correction [7], [8].

Third-level transformers provide many advantages over two-level transformers, such as improved output voltage quality, higher voltage operability, and reduced pressure on $\mathrm{dv} / \mathrm{dt}$. It enables the construction of a high-power transformer without the problem of switching the series-connected semiconductor devices [9]. Due to these 
features, the third level transformers are increasingly used in high and medium / high power applications such as electric traction system, AC power transmission, Far static compensators [10].

\section{PRINCIPLE OF OPERATION}

Figure 1 shows a STATCOM circuit diagram based on a three-phase and three-level neutral voltage reflector (NPC). The main component is the inverter which consists of 12 switches and 16 diode connected to the electrical current through the transformer, and the leakage of the transformer is represented by XL [11], [12].

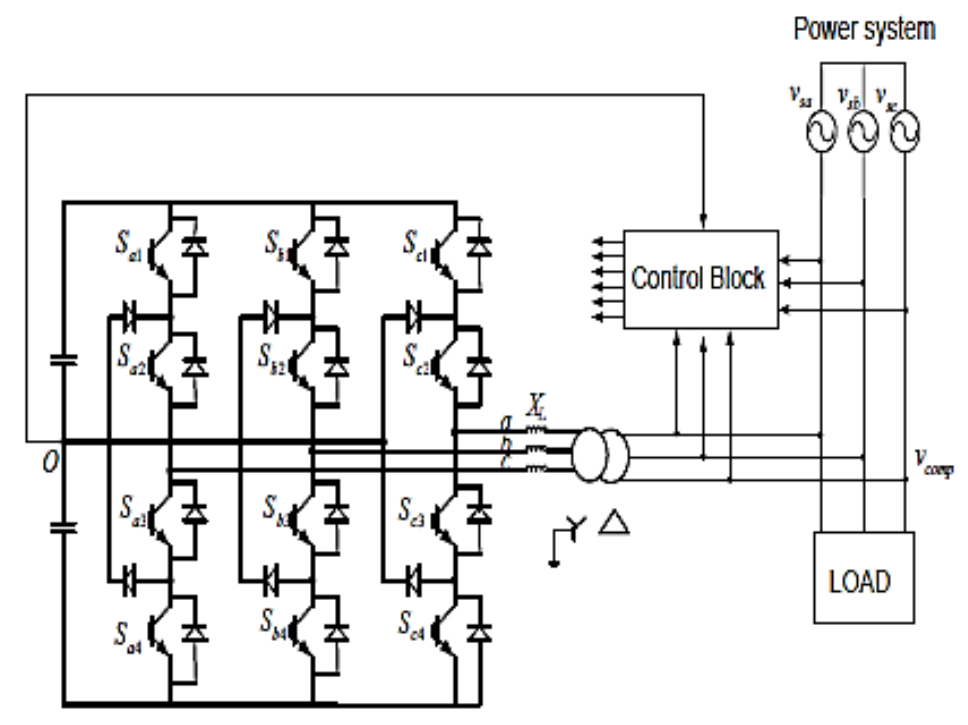

Figure 1. The power-circuit of ASVC, using a 3-level inverter

Proper control of the DC current voltage is necessary to operate the compensator. The principle of direct current voltage control is based on active energy control, that is, charging a DC capacitor with an active force will increase the voltage, while releasing a certain amount of active energy will reduce it. According to pq theory, the DC component in dq coordinates corresponds to the active power, and therefore the DC-bus voltage control is applied in the synchronous reference frame [13]. Figure 2. The basic parabolic circuit for each stage of STATCOM is shown in Figure 2. These diagrams can be used to explain the principles of STATCOM operation.

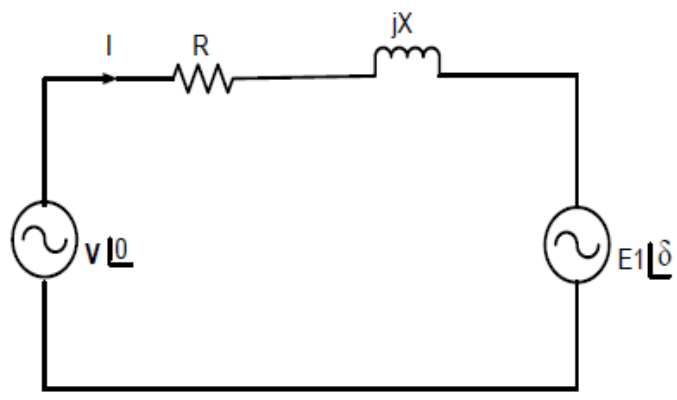

Figure 2. Per-phase equivalent circuit of STATCOM at fundamental frequency

\section{A. Control Circuit}

The block diagram of the control circuit of the STATCOM is shown in Fig. 3. It consists of a proportional plus (PI) controller, snake, a voltage controlled oscillator (VCO), a counter and a switch pattern. The source voltage and current are converted to the d-q frame to calculate the system's reactive power. This is compared to the var reference. The VCO output frequency is synchronized to the AC supply frequency. Under steady-state operating conditions $(\delta=0)$, the request signal var is zero and the switching pattern stored at the supply frequency, fo. If the load factor fluctuates, the calculated var will change and VCO will either accelerate or slow down to correct the error. 


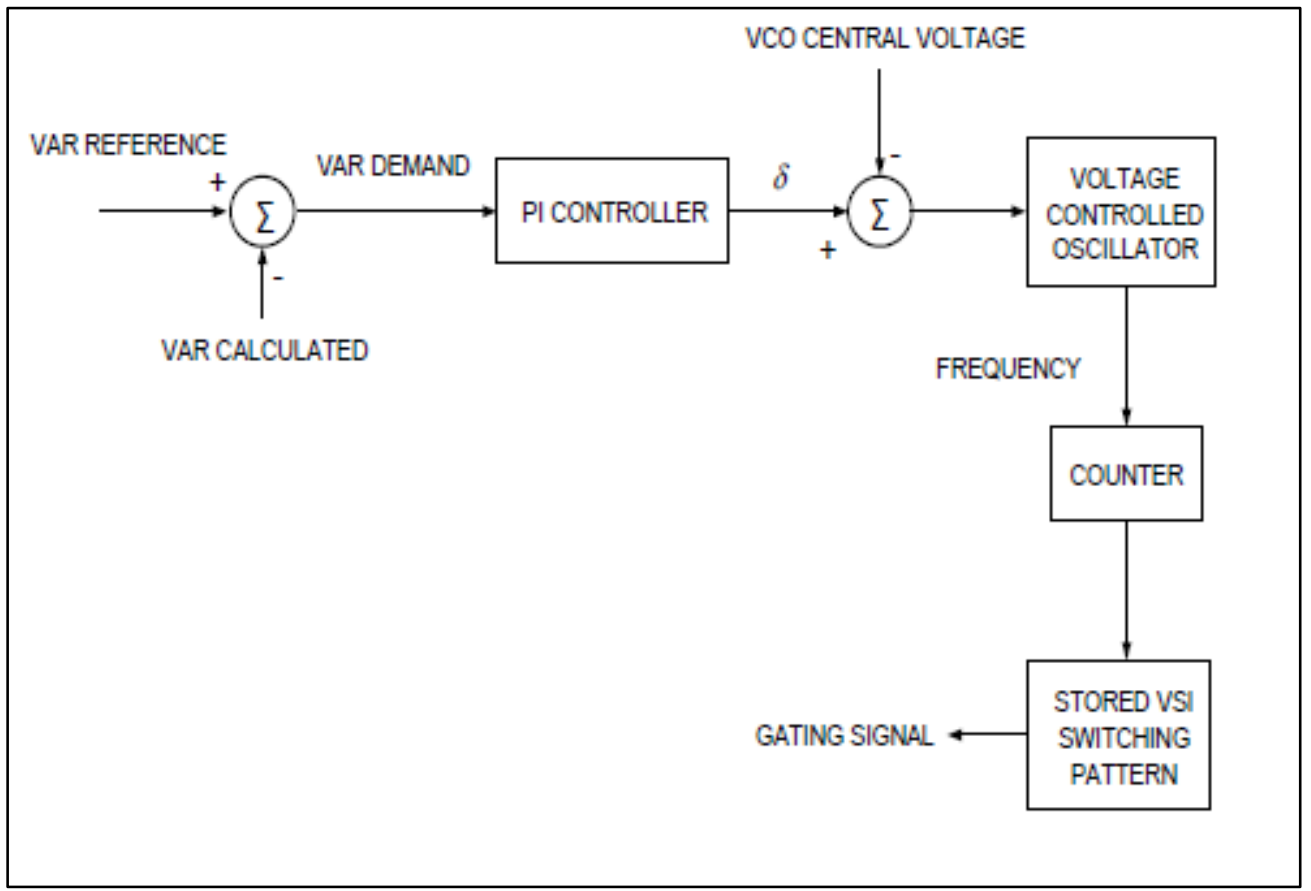

Figure 3. The $\delta$ Phase-shift control block diagram

\section{B. Fundamental Frequency Modulation (FFM)}

Figure 4 shows the line and line waveforms obtained in the three-level reflector by applying a switching system to obtain the output voltage that has breaks when the output is zero as well. The amplitude can be controlled by setting the $\alpha$ interval on each side of the pulse where the result is zero.

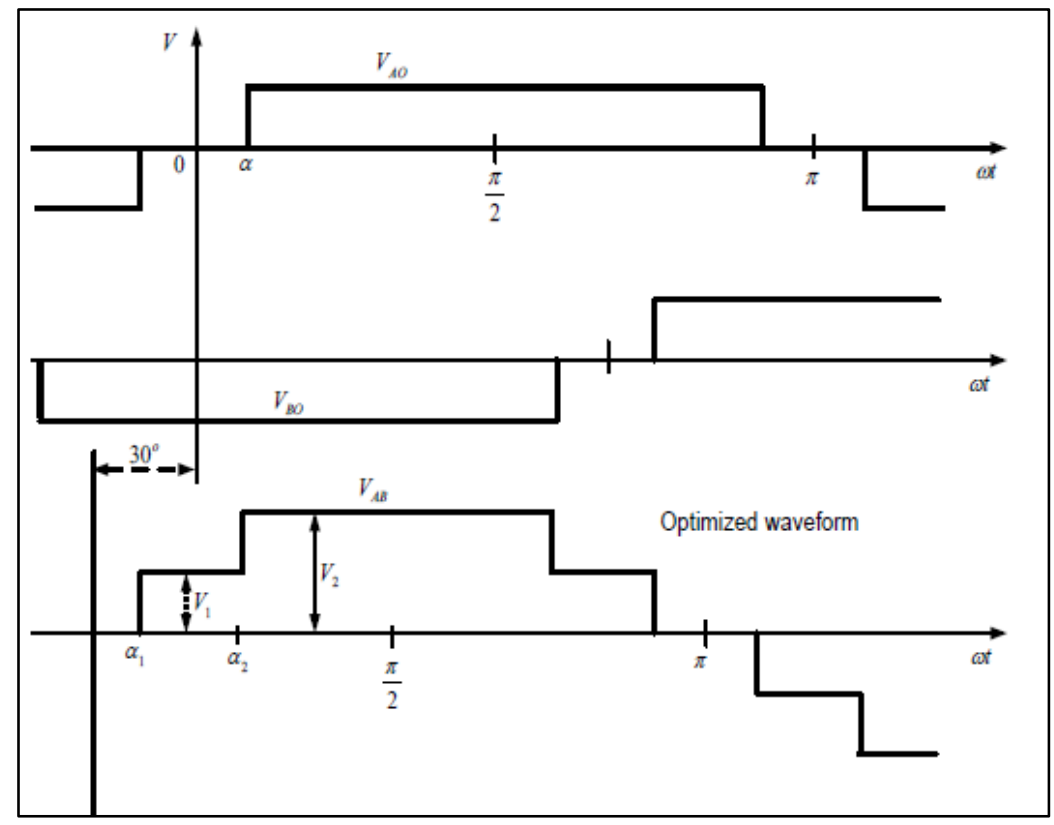

Figure 4. Typical FFM phase and line voltages in three-level inverter

In Fig.4, the phase voltage VOA is given by the Fourier expression:

$$
V_{O A}=\sum_{n=1}^{\infty} b_{n} \sin n \omega t
$$


Where, $b_{n}=\frac{4 V_{i}}{n \pi} \cos n \alpha$. $\rightarrow 2$

This three-level voltage has an additional advantage of better wave quality, Low Total Harmonic Distortion (THD), and Low Electromagnetic Interference (EMI) over two-level counterparts. The harmonic amplitudes of the conventional waveform and the optimized waveform are shown in Table 1. It can be seen from the table that THD has decreased from 31.08 to 16.86 , and this is achieved by maintaining the same average power output in the proposed system as that of a conventional PWM inverter on two levels.

Table 1: Proportional amplification values for the percentage of voltage resulting from the inverter voltage

\begin{tabular}{|lll|}
\hline \hline \multirow{2}{*}{ Harmonic Number } & $\frac{b_{n}}{b_{1}} \%$ (conventional) & $\frac{b_{n}}{b_{1}} \%$ (optimized) \\
\hline 1 & 100 & 100 \\
5 & 20 & 0 \\
7 & 14.28 & 3.8 \\
11 & 9.09 & 9.09 \\
13 & 7.69 & 7.69 \\
17 & 5.88 & 1.58 \\
19 & 5.26 & 1.41 \\
23 & 4.35 & 4.35 \\
25 & 4.0 & 4.0 \\
29 & 3.45 & 0.92 \\
31 & 3.22 & 0.86 \\
35 & 2.86 & 0.86 \\
THD \% & 31.08 & 16.86 \\
\hline \hline
\end{tabular}

\section{DESIGN OF STATCOM}

System power factor can be improved by installing STATCOM near load. Taking MI $=0.8$ and $\mathrm{R}=0.5 \Omega$, (22) were solved to obtain the values of $\delta$ and $\mathrm{L}$ that met the requirements for voltage regulation and power factor (pf) of the ac system, i.e. $0.96<\mathrm{pf}<1.0$. So, for the unit power factor, Figure 5 shows the output voltage, compensated voltage.

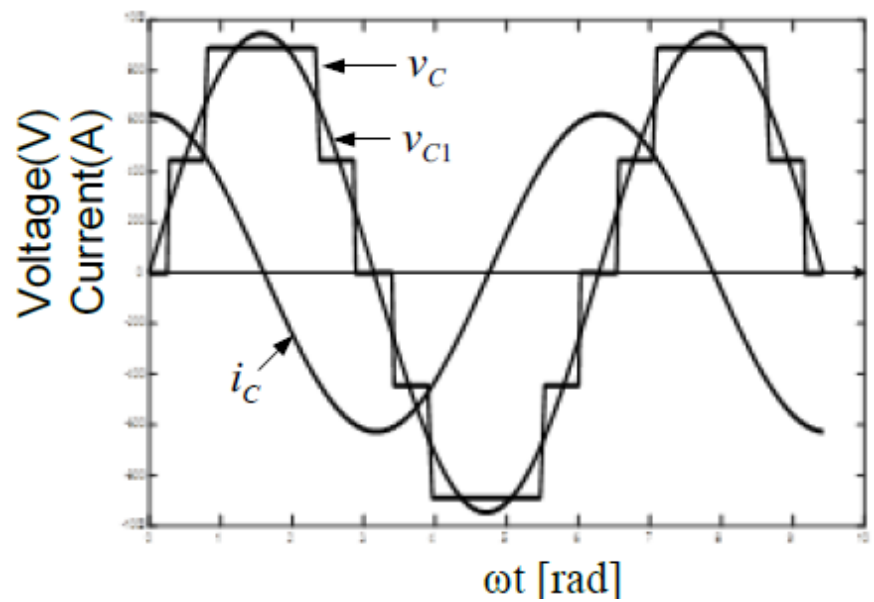

Figure 5. Compensator output voltage and current $v c$-output voltage vcl-fundamental component ic-output current 


\section{CONCLUSION}

In this paper we have shown how to improve the operation of the AC system through the application of STATCOM, using the inverter of the FFM voltage source. The system power factor was raised from 0.76 to the unit, which reduced the power line from 112.75A to 88.3A, which resulted in an effective decrease in energy loss by $38.7 \%$, thus reducing energy costs, as well as increasing the capacity of the transmission system. The presence of STATCOM also reduced the on-line interactive power flow from 2.791 MVAr per stage (qL in Figure 5) to 1745 $\mathrm{VAr}$ per stage. Thus it can be seen that the receiving end voltage at the loading conveyor has been raised from $60 \mathrm{kV}$ to $66 \mathrm{kV}$ due to the voltage generated by STATCOM.

The power factor (pf) can be found from: $\quad p f=\cos \left[\tan ^{-1}\left(\frac{1745 .}{3.27 * 10^{6}}\right)\right]=1.0$

It can be seen that the reactive elements $(\mathrm{L}$ and $\mathrm{C})$ are small.

\section{REFERENCES}

1. Karthick, R and Sundararajan, M: "A Reconfigurable Method for TimeCorrelatedMimo Channels with a Decision Feedback Receiver,” International Journal of Applied Engineering Research 12 (2017) 5234.

2. Karthick, R and Sundararajan, M: "PSO based out-of-order (ooo) execution scheme for HT-MPSOC"Journal of Advanced Research in Dynamical and Control Systems 9 (2017) 1969.

3. Karthick, R and Sundararajan, M: "Design and Implementation of Low Power Testing Using Advanced Razor Based Processor," International Journal of Applied Engineering Research 12 (2017) 6384.

4. Karthick, R and Sundararajan, M: "A novel 3-D-IC test architecture-a review," International Journal of Engineering and Technology (UAE)7 (2018) 582.

5. R.Karthick, P Selvaprasanth, A ManojPrabaharan, "Integrated System For Regional Navigator And Seasons Management," Journal of Global Research in Computer Science 9(4),2018(11-15).

6. Karthick, R and Prabaharan, A.Manoj and Selvaprasanth, P. and Sathiyanathan, N. and Nagaraj, A., High Resolution Image Scaling Using Fuzzy Based FPGA Implementation (March 15, 2019). Asian Journal of Applied Science and Technology (AJAST), Volume 3, Issue 1, Pages 215-221, Jan-March 2019 . Available at SSRN: https://ssrn.com/abstract=3353627

7. Karthick, R and Sundararajan, M., Hardware Evaluation of Second Round SHA-3 Candidates Using FPGA (April 2, 2014). International Journal of Advanced Research in Computer Science \& Technology (IJARCST 2014), Vol. 2, Issue 2, Ver. 3 (April - June 2014). Available at SSRN: https://ssrn.com/abstract=3345417.

8. Karthick, R and and Prabaharan, A.Manoj and Selvaprasanth, P.,Internet of Things based High Security Border Surveillance Strategy (May 24, 2019). Asian Journal of Applied Science and Technology (AJAST), Volume 3, Issue 2, Pages 94-100, Apr-June 2019. Available at SSRN: https://ssrn.com/abstract= 3394082.

9. Karthick, R and Sundararajan, M: "SPIDER based out-of-order (ooo) execution scheme for HT-MPSOC" International Journal of Advanced Intelligence paradigms, In Press. 
10. Karthick, R and John Pragasam, D "Design of Low Power MPSoC Architecture using DR Method" Asian Journal of Applied Science and Technology (AJAST) Volume 3, Issue 2, Pages 101-104, April -June 2019.

11. Karthick, R and Sundararajan, M., Optimization of MIMO Channels Using an Adaptive LPC Method (February 2, 2018). International Journal of Pure and Applied Mathematics, Volume 118 No. $102018,131-135$. Available at SSRN: https://ssrn.com/abstract=3392104

12. Karthick, R and Rinoj, B. Micheal Vinoline and Kumar, T. Venish and Prabaharan, A.Manoj and Selvaprasanth, P., Automated Health Monitoring System for Premature Fetus (July 27, 2019). Asian Journal of Applied Science and Technology (AJAST) (Peer Reviewed Quarterly International Journal) Volume 3, Issue 3, Pages 17-23, July -September 2019. Available at SSRN: https://ssrn.com/abstract=3427756

13. Karthick, R.,Deep Learning For Age Group Classification System, International Journal Of Advances In Signal And Image Sciences. Volume 4, Issue 2, Pages 16-22, 2018.

14. R. Karthick, N.Sathiyanathan, "Medical Image Compression Using View Compensated Wavelet Transform" Journal of Global Research in Computer Science 9(9), 2018(1-4).

15. P. Meenalochini and S. P. Umayal, Comparison of Current Controllers on Photo Voltaic Inverters Operating as VAR Compensators, Journal of Electrical Engineering The Institution of Engineers, Bangladesh Vol. EE 38, No. I, June, 2012. 